\title{
REWORK IN HIGHWAY PROJECTS
}

\author{
Nuria FORCADA ${ }^{\mathrm{a}}$, Gerard RUSIÑOL ${ }^{\mathrm{a}}$, Marcel MACARULLA ${ }^{\mathrm{a}}$, Peter E. D. LOVE \\ ${ }^{a}$ Department of Construction Engineering, Universitat Politècnica de Catalunya, Terrassa, Spain \\ ${ }^{b}$ School of Built Environment, Curtin University, Perth, Australia
}

Received 06 Nov 2012; accepted 07 Jan 2013

\begin{abstract}
There is limited systematic knowledge available about the dynamics of rework in highway projects, despite the fact that they frequently exceed budget and schedule by more than $10 \%$. A case study of a Spanish highway project, which experienced a significant cost overrun as a result of rework, is examined and the causal factors that contributed to its occurrence are determined. Through observation and subsequent analysis of interviews and documentation a high degree of interdependency existed between perceived causes of rework. This resulted in the nomenclature of Project, Organization and People to be adopted and used to develop the rework generic systemic model. Scope changes, high complexity, poor skill levels and unexpected underground services were found to be the most significant causes of rework. The developed model provides managers with insights about the interdependencies and behaviour between key influencing variables in highway projects and can be used to stimulate learning and process improvements in future highway projects.
\end{abstract}

Keywords: highway projects, rework, system dynamics.

Reference to this paper should be made as follows: Forcada, N.; Rusiñol, G.; Macarulla, M.; Love, P. E. D. 2014. Rework in highway projects, Journal of Civil Engineering and Management 20(4): 455-465.

http://dx.doi.org/10.3846/13923730.2014.893917

\section{Introduction}

The highway transport sector in Spain represents 2.62\% of the Gross Domestic Product and employs 3.05\% of the working population, making it one of the most important in Europe (Montes 2007). Although the public spending in Spain decreased $37.9 \%$ from 2009 to 2010 , highways are the most important sector and represent $37.4 \%$ of the total public investment (Ministerio de Fomento 2011). Considering the importance of highway projects in Spain it is imperative that they are delivered on time and to budget.

Cost overruns in transportation infrastructure projects, such as highways have been identified as being attributable to errors and the subsequent rework that often occurs (Barber et al. 2000; Love et al. 2012a). The determination of rework costs in highway projects has been limited to date (e.g. Barber et al. 2000; Love et al. 2012a). However, having to unnecessarily redo work that was incorrectly undertaken the first time is a pervasive problem in construction and engineering projects (Rogge et al. 2001; Love 2002; Dissanayake et al. 2003; Love, Edwards 2004; Fayek et al. 2004; Palaneeswaran et al. 2008; Hwang et al. 2009; Zhang et al. 2012).

Rework often arises from design changes, errors, and omissions that often stem from scope uncertainty and the contracting strategy adopted (Burati et al. 1992; Love et al. 2011). The inherent degree of uncertainty that prevails within transportation infrastructure projects can result in their planning being a problematic issue, especially when information is not readily available. As a result this can affect decision-makers choices during the formative stages of a project (Alessandri et al. 2004). In the absence of available knowledge, decisions that are undertaken prior to, or during construction may be erroneous and may even lead to disastrous consequences arising (Love et al. 2012b). When uncertainty is high, initial drawings and specifications will invariably change, and the project team will have to solve problems as they arise during construction. Once changes arise they may be deemed to be ambiguous and as a result lead to disagreements between parties (Williamson 1979).

Faced with underestimation of costs during the bidding process, the project team tends to rely on scope changes or missing units in the budget to recover benefits. Once changes arise they may be deemed to be ambiguous, erroneous and invariably require rework. Rework, on average, contributes to $52 \%$ of a total cost overrun incurred and can increase schedule overrun by $22 \%$ (Love 2002). Rework costs have been found to range from $5 \%$ to $20 \%$ of contract value in construction and engineering projects with design scope changes rework accounting for as much as $50 \%$ of the rework that occurs (e.g. Barber et al. 2000; Love, Edwards 2004). Yet, limited knowledge exists about rework costs in highway projects, even though such costs can have a negative impact on project performance and organizations profitability. 
With this in mind, the causal nature of rework that arose in eight highway projects is examined. The findings are used to develop an influence diagram, based on the concept of system dynamics, to determine the interrelationships between variables that contributed to rework as well as time and cost overruns experienced. The developed model will enhance understanding about the dynamics of rework and therefore stimulate learning and process improvement. A detailed review of rework costs and causes in construction and engineering projects can be found in Hwang et al. (2009) and Zhang et al. (2012).

\section{Research approach}

System dynamics is an appropriate modelling technique for analysing or managing complex processes, which involve changes over time and are dependent on the feedback, transmission, and receipt of information (Love et al. 2008). System dynamics is defined as "a rigorous method for qualitative description, exploration, and analysis of complex systems in terms of their processes, information, organizational boundaries, and strategies; which facilitates quantitative simulation modelling and analysis for the design of system structure and behaviour" (Wolstenholme 1990). System dynamics also "offers a rigorous method for the description, exploration, and analysis of complex project systems comprised of organizational elements, the project work packages and environmental influences" (Rodrigues, Bowers 1996). The method has been used as a project post-mortem diagnosis tool (Cooper 1980; Williams et al. 1995). Consequently, and in this specific context, it can be used to provide managers with the necessary insights about the interdependencies and behaviour between key variables that can contribute to rework so that learning and process improvements can be made to future projects (Cooper 1993; Love et al. 2008). The technique of influence diagramming, an embedded function of system dynamics, is used in this paper to provide the platform for linking the major causal variables of rework in a major highway construction project.

\subsection{Case study}

A case study approach based upon analytic induction is used to examine the underlying dynamics that may contribute to rework in highway projects. A case study is exploratory in nature, based on interviews and relies heavily on verbal reports and unobtrusive observation as data sources. This methodology should be used to investigate the technical aspects of a contemporary phenomenon within a real life context (Yin 1984), particularly in critical and unique circumstances (Flyvbjerg 2006). It is particularly useful when the boundaries between phenomenon and context are difficult to ascertain and when multiple sources of evidence are used (Yin 1984). A case study can provide analytical rather than pure statistical generalizations and can capture the complexity and dynamism of organizational settings in projects (Flyvbjerg 2006).
Analytic induction refers to a systematic examination of similarities between various social phenomena to develop generic concepts or ideas. It facilitates modification of social concepts and their relationships throughout the research process, with the goal of most accurately representing the reality of the situation (Ragin 1994). No analysis, however, can be considered final as reality is inexhaustible and dynamic (Znaniecki 1934). The determination of causal events that lead to rework can explain the interaction that can exist between variables. The conjunction of events can result in orthodoxies being established and through the process of observation, generalizations can be made. If such generalisations can be repeatedly tested and confirmed, they can lead to the discovery of a lawful relationship.

\subsection{Data collection}

The researchers acted as non-participant observers throughout the duration of the data collection process onsite. Data was collected from the date on which construction commenced onsite to the date of practical completion. The case study was chosen due to its complexity and unique approach used to award contracts. The entire project was designed and documented by the same engineering consulting firm, and was then divided into a series of individual projects, which were awarded to different contractors. This was the first time in Spain that public infrastructure works implemented different contractors and contractual arrangements within one project.

The project comprised of eight sub-projects which was visited between one and three times a week throughout their duration. Each visit lasted between one and three hours. The time allocated for organising rework data varied because during the early stages of the project the contractor identified and reported few incidents. Block visits of four days were also conducted in each project to coincide with increased periods of site activity. The researchers acted as observers and at times, relied on their industry experience to identify rework events that occurred while reading through the contract documentation (i.e. site instructions, change order requests, requests for information, drawing changes, etc.), which was stored in the main site offices. However, before any event was categorized as rework, its validation was sought from the contractor's project manager, site foreman, and contract's administrator. Every attempt was made not to disrupt the workflow of the site management team and subcontractors.

The research relied on reports of individuals' historical events that are open to biases to do with recall and self-presentation. Independent verification of the inferences made from interviewees was made. Multiple sources were used to triangulate these data so as to obtain a balanced view of the problem at hand. Triangulation was used to cross check for internal consistency and reliability, and to test the degree of external validity of the data. Documentation provided by the contractor and unstructured interviews with project team members (e.g. architect, structural/mechanical/electrical engineers, site management team, and subcontractors) were the primary sources 
of information for determining the causes and the costs of rework that were experienced. A total of 45 interviews with the client's representative/project manager, design consultants, the contractor, subcontractors, and end-users, which ranged from 20 to $90 \mathrm{~min}$ in duration, were undertaken during the project's construction phase. Once a rework event was identified, then all parties involved with identification and rectification were interviewed so a balanced view of the event could be established. Data derived from the interviews were transcribed and then given to the interviewee to check for any discrepancies that may have arisen.

\subsection{Data analysis}

The text derived from the documents and interviews was analysed using the QSR NVivo 9 software. This software is used to organize and analyse unstructured information with powerful processes of indexing and theorising. Fundamentally QSR NVivo 9 enables the presence of certain words or concepts within texts or sets of texts to be determined. This can enable the researcher to quantify and analyse the presence, meanings and relationships of words and concepts, then make inferences about the messages contained within the texts. QSR NVivo 9 also enabled additional data sources and journal notes to be incorporated into the analysis as well as identify new emergent themes. The development and re-assessment of themes as analysis progresses accords with the calls for avoiding confining data to pre-determined sets of categories (Silverman 2001). Kvale (1996) suggests that ad hoc methods for generating meaning enable the researcher to access "a variety of common-sense approaches to interview text using an interplay of techniques such as noting patterns, seeing plausibility, making comparisons etc." (204 p.). Using QSR NVivo 9 facilitated an organic approach to coding as it enabled triggers or categories of textural interest to be coded and used to monitor emerging and developing ideas (Kvale 1996). These coding can be modified, integrated or migrated as the analysis progresses and the generation of reports, using Boolean search, facilitates the recognition of conflicts and contradictions.

Coding, if done well, "is the way you monitor occurrences of data about your ideas and the way you test them. It makes resilient links between data and ideas, links that you can trace back to find where particular ideas came from and what data are coded there, to justify and account for the interpretation of the ideas" (Morse, Richards 2002). Coding was undertaken systematically to ensure the data was treated equally. The initial step in the analysis was to read the interview transcripts. The transcription process itself was used for initial analysis, with the researcher recording notes while transcribing. These initial notes were used to formulate categories, and connect themes, and help to begin to think about contextual relationships between them.

The analysis commenced by examining themes associated with 'change', 'error', 'cost' and 'mistakes'. Using an inbuilt function within QSR NVivo 9, words with similar meanings such as mistake and error were identified. The automated function of word frequency query was used to determine the most used words in selected materials ('sources'). A researcher can manoeuvre from one data source to the next using features called 'doc links, 'node links' and 'data links'. The researcher creates 'nodes' to mark relevant concepts and topics in text documents that can be searched and analysed. These codings were modified, integrated or migrated as the analysis progresses and the generation of reports, using Boolean search, facilitated the recognition of conflicts and contradictions.

From NVivo analysis a high degree of interdependency was perceived between rework sources. This resulted in the nomenclature of Project, Organization and People to be adopted like in a previous study from Love et al. (2012a). Organization group includes: Scope definition; Inappropriate design; No information about the site; Wrong material selection; Pressure to start execution; Pressure to finalize works; Commencement of construction before design completed; Inadequate interface management between contractors and consultants; Discrepancies between the administration and the management team; Poor supervision; Lack of adherence of quality control and Lack of construction knowledge. Management group includes: Lack of communication; Lack of design audits; Lack of knowledge management; Inadequate skills and knowledge; Lack of planning and resources; Inadequate coordination with other projects; Lack of staff supervision; Ineffective implementation of QA; and Inadequate training. And finally People group includes: Stress; Slips; Lack of experience and expertise; Omission of checks; and Wrong distribution of information and Misinterpretation due to lack of knowledge.

\subsection{Case background}

The project had a contract value of 48,989,409.44 $€$ and involved a $115 \mathrm{~km}$ lane extension to the AutoPista (AP) 7 highway from the Mediterranean junction AP-2, to Vilaseca/Salou. It was a concession contract for ACESA (Autopistas Concesionaria Española S.A.) to develop this works to improve the public service of the highway. ACESA was the responsible to submit the project to competition. In addition, several underpasses and bridges were required and as a result the project was divided into eight sub-projects (Table 1 and Fig. 1). Each subproject was competitively awarded under a separate works contract.

\section{Rework causation}

The selected projects experienced significant cost overruns due to changes, errors, omissions, which resulted in the occurrence of rework. Despite the presence of rework it was not formally measured, as there was a perception that such recognition could potentially damage the organization's corporate image. While additional costs could be identified and attributable to an event, for example, an error on a drawing, rework was an uncomfortable term for the contractor as it had a negative connation. However, the contractor was curious to know 'why' and 'how' 
Table 1. Projects' details

\begin{tabular}{|c|c|c|c|c|c|c|}
\hline $\begin{array}{l}\text { Project } \\
\text { ID }\end{array}$ & Sub-project Type & Ocv€ & Acv€ & $\begin{array}{l}\text { Rework as } \\
\% \text { of Ocv }\end{array}$ & $\begin{array}{c}\text { Cost } \\
\text { increase } \\
(\%)\end{array}$ & $\begin{array}{c}\text { Schedule } \\
\text { increase } \\
(\%)\end{array}$ \\
\hline 1 & $\begin{array}{l}\text { Extension of the structure from } \\
211+329 \text { kilometric point (KP) } \\
\text { to } 227+000 \mathrm{KP}\end{array}$ & $1,193,293$ & $1,795,619$ & Unknown & 50.5 & - \\
\hline 2 & $\begin{array}{l}\text { Extension of the structure from } \\
227+000 \mathrm{KP} \text { to } 256+288 \mathrm{KP}\end{array}$ & $1,322,944$ & $2,118,960$ & Unknown & 60.2 & - \\
\hline 3 & Masonry extension $420.5 \mathrm{KP}$ & $3,766,431$ & $4,900,202$ & 14.0 & 30.1 & - \\
\hline 4 & Masonry Remodelling $210.8 \mathrm{KP}$ & 376,136 & 427,462 & 8.3 & 13.6 & - \\
\hline 5 & $\begin{array}{l}\text { Extension of the platform from } \\
210+478 \mathrm{KP} \text { to } 234+001 \mathrm{KP}\end{array}$ & $16,770,836$ & $32,260,203$ & 31.2 & 92.4 & 3 months \\
\hline 6 & $\begin{array}{l}\text { Extension of the platform from } \\
234+001 \mathrm{KP} \text { to } 256+\mathrm{KP}\end{array}$ & $14,926,805$ & $21,704,742$ & 13.0 & 45.4 & 4 months \\
\hline 7 & $\begin{array}{l}\text { Paving surface and horizontal } \\
\text { signalling from } 210+478 \mathrm{KP} \text { to } \\
256+288 \mathrm{KP}\end{array}$ & $8,504,534$ & $10,235,866$ & 17.0 & 20.4 & 2 days \\
\hline 8 & $\begin{array}{l}\text { Adaptation of the vehicles } \\
\text { containment system }\end{array}$ & $2,128,427$ & $3,060,635$ & 16.0 & 43.8 & 2 months \\
\hline
\end{tabular}

Project 1

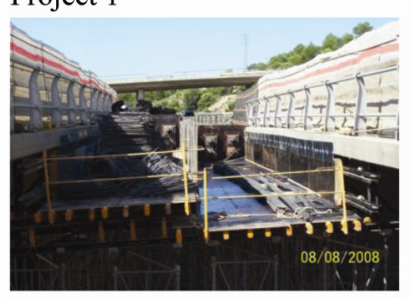

Project 3

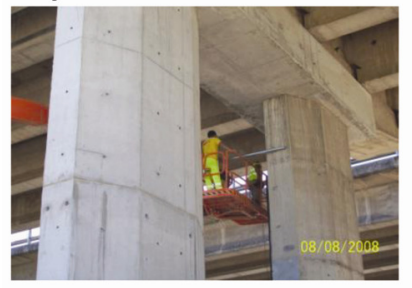

Project 5

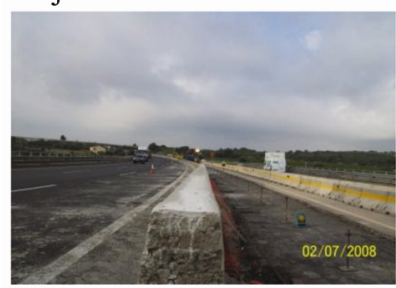

Project 7

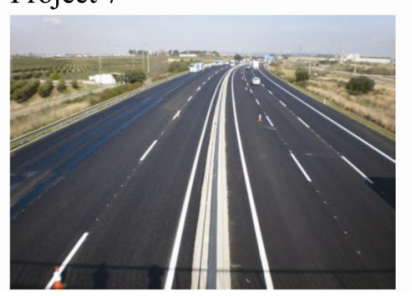

Fig. 1. AutoPista (AP) 7 highway
Project 2

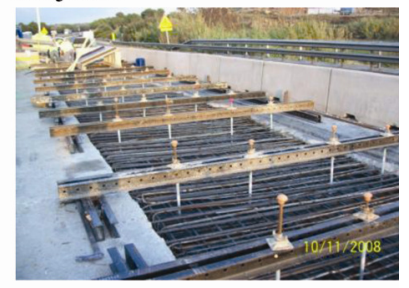

Project 4

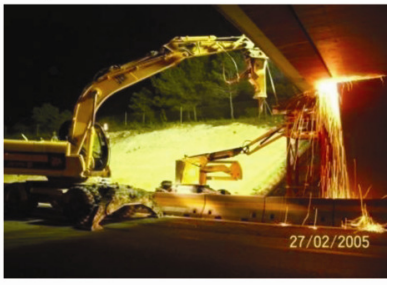

Project 6

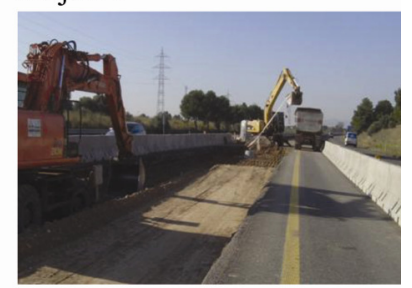

Project 8

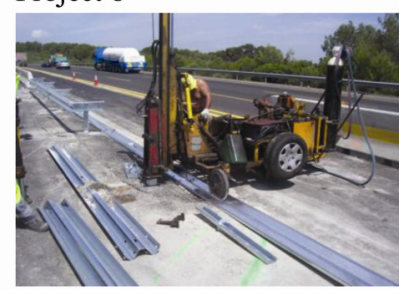

rework arose in their project. Through observation and subsequent analyse of interviews and documentation a taxonomy of rework causes based upon Project, Organization and People (POP) is presented in Table 2. Love et al. (2012a) have undertaken similar research and revealed that rework could also be classified accordingly. The taxonomy has enabled the common factors contributing to rework in the sub-projects to be identified. In deriving the POP taxonomy each sub-project is examined herein after.

Client changes and rework in each sub-project contributed to cost increases, though it was difficult to determine these amounts in sub-project 1 and 2. Noteworthy, with the exception of project 3, no significant schedule overruns were experienced. In sub-project 3 , the commencement of construction was delayed for 9 months due to contractual negotiations. Project 5 experienced a significant amount of non-conformances, which led to rework and an extension of time. In an effort to meet the project's scheduled completion date, additional resources were employed and tasks were carried out concurrently, which lead to the opposite of the desired effect, as a significant delay occurred. This scenario is commonly referred to as Brookes Law. By pushing beyond the limits of acceptable levels of concurrency, complexity increases and destabilises the project. This further increases the time to complete tasks, particularly when revisions, repairs and rework occur. In this instance a rework cycle may commence (Cooper 1980).

As noted in Table 2, sub-project 6 was delayed by four months, of which two months were attributable to extensions for scope changes. In sub-project 7 however no time extension was given for the rework that arose. Rework accounted for $16.5 \%$ of the project's total cost overrun. This data is significantly lower than that the reported $50 \%$ of a total project's cost overrun found in a sample of 161 construction projects (Love 2002). 
Table 2. Factors influencing rework

\section{Factors influencing rework}

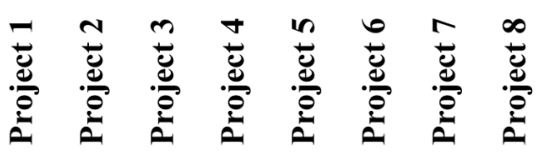

\begin{tabular}{|c|c|c|c|c|c|c|c|c|}
\hline Project & & & & & & & & \\
\hline Scope definition & $\sqrt{ }$ & $\sqrt{ }$ & & & $\sqrt{ }$ & $\sqrt{ }$ & $\sqrt{ }$ & $\sqrt{ }$ \\
\hline Inappropriate design & & $\sqrt{ }$ & $\sqrt{ }$ & & $\sqrt{ }$ & $\sqrt{ }$ & & $\sqrt{ }$ \\
\hline No information about the site & $\sqrt{ }$ & $\sqrt{ }$ & & & $\sqrt{ }$ & & & \\
\hline Wrong material selection & & & $\sqrt{ }$ & & & & $\sqrt{ }$ & \\
\hline Pressure to start execution & & & & & $\sqrt{ }$ & $\sqrt{ }$ & $\sqrt{ }$ & $\sqrt{ }$ \\
\hline Pressure to finalize works & & & & $\sqrt{ }$ & $\sqrt{ }$ & $\sqrt{ }$ & $\sqrt{ }$ & $\sqrt{ }$ \\
\hline Commencement of constr. before design completed & & & & & & $\sqrt{ }$ & & $\sqrt{ }$ \\
\hline $\begin{array}{l}\text { Inadequate interface management between contractors and } \\
\text { consultants }\end{array}$ & $\sqrt{ }$ & $\sqrt{ }$ & $\sqrt{ }$ & & $\sqrt{ }$ & $\sqrt{ }$ & $\sqrt{ }$ & $\sqrt{ }$ \\
\hline Discrepancies between the adm. and the man. team & & $\sqrt{ }$ & $\sqrt{ }$ & $\sqrt{ }$ & $\sqrt{ }$ & $\sqrt{ }$ & & $\sqrt{ }$ \\
\hline Poor supervision & $\sqrt{ }$ & $\sqrt{ }$ & $\sqrt{ }$ & $\sqrt{ }$ & $\sqrt{ }$ & $\sqrt{ }$ & & $\sqrt{ }$ \\
\hline Lack of adherence of quality control & $\sqrt{ }$ & & & & & & & $\sqrt{ }$ \\
\hline Lack of construction knowledge & $\sqrt{ }$ & & & & & & $\sqrt{ }$ & $\sqrt{ }$ \\
\hline \multicolumn{9}{|l|}{ Organization } \\
\hline Lack of communication & $\sqrt{ }$ & $\sqrt{ }$ & $\sqrt{ }$ & $\sqrt{ }$ & $\sqrt{ }$ & & $\sqrt{ }$ & \\
\hline Lack of design audits & $\sqrt{ }$ & $\sqrt{ }$ & $\sqrt{ }$ & $\sqrt{ }$ & $\sqrt{ }$ & $\sqrt{ }$ & $\sqrt{ }$ & $\sqrt{ }$ \\
\hline Lack of knowledge management & & $\sqrt{ }$ & $\sqrt{ }$ & $\sqrt{ }$ & $\sqrt{ }$ & $\sqrt{ }$ & & $\sqrt{ }$ \\
\hline Inadequate skills and knowledge & $\sqrt{ }$ & $\sqrt{ }$ & $\sqrt{ }$ & $\sqrt{ }$ & $\sqrt{ }$ & $\sqrt{ }$ & $\sqrt{ }$ & $\sqrt{ }$ \\
\hline Lack of planning and resources & & & & & & $\sqrt{ }$ & & $\sqrt{ }$ \\
\hline Inadequate coordination with other projects & $\sqrt{ }$ & & $\sqrt{ }$ & & $\sqrt{ }$ & $\sqrt{ }$ & & $\sqrt{ }$ \\
\hline Lack of staff supervision & & & & $\sqrt{ }$ & $\sqrt{ }$ & $\sqrt{ }$ & $\sqrt{ }$ & $\sqrt{ }$ \\
\hline Ineffective implementation of QA & $\sqrt{ }$ & & & & $\sqrt{ }$ & $\sqrt{ }$ & & $\sqrt{ }$ \\
\hline Inadequate training & & & $\sqrt{ }$ & $\sqrt{ }$ & $\sqrt{ }$ & $\sqrt{ }$ & $\sqrt{ }$ & $\sqrt{ }$ \\
\hline \multicolumn{9}{|l|}{ People } \\
\hline Stress (due to work overload) & & & & & $\sqrt{ }$ & $\sqrt{ }$ & $\sqrt{ }$ & $\sqrt{ }$ \\
\hline Slips & $\sqrt{ }$ & & $\sqrt{ }$ & & $\sqrt{ }$ & $\sqrt{ }$ & $\sqrt{ }$ & $\sqrt{ }$ \\
\hline Lack of experience and expertise & $\sqrt{ }$ & & & & & $\sqrt{ }$ & & $\sqrt{ }$ \\
\hline Omission of checks & & $\sqrt{ }$ & & & & $\sqrt{ }$ & & $\sqrt{ }$ \\
\hline Wrong distribution of information & & $\sqrt{ }$ & & & $\sqrt{ }$ & $\sqrt{ }$ & & $\sqrt{ }$ \\
\hline Misinterpretation due to lack of knowledge & $\sqrt{ }$ & & & $\sqrt{ }$ & $\sqrt{ }$ & $\sqrt{ }$ & & $\sqrt{ }$ \\
\hline
\end{tabular}

\section{Project 1: Extension of the structure}

Within this sub-project incorrect information about existing site conditions were provided to the design consultants, which subsequently led to errors within the contract documentation. The execution of a transition slab in the bracket of the existing bridges structures was wrongly performed, which was not identified until the project was almost complete. As result, a dispute between the client and the contractor was initiated. According to the Art 213 Ley 30/2007 de Contratos del Sector Público (Jefatura de Estado 2007) (law of public sector contracts), the contractor must follow the project documentation, the Project
Manager instructions and/or the administration instructions during the construction process and the warranty period. In this particular instance, after commissioning the contractor would not accept responsibility for repairing the irregularities that were identified. The contractor argued the client's project management team did not find any quality deviations while the transition slab was being installed. If the quality deviation had been identified, then the contractor would have rectified it immediately. The client denounced the contractor for not satisfying the conditions of the period of warranty and for the responsibility of hidden defects. This situation could have been avoided if supervisions and inspections had been regular- 
ly undertaken by the client's project management team. It would appear miscommunication and poor coordination between both parties contributed to the issue at hand.

\section{Project 2: Extension of the structure}

In project 2, incomplete contract documentation and lack of detailed analysis of the existing services and soil conditions were fundamentally the factors contributing to rework in this sub-project as:

- no provision had been made within the contract documentation for micro piles to be included in the. Fundamentally, an omission error was made; and

- no risk analysis was carried out, so during the execution of the foundations for the new pillars of the structure, instead of shoes, micro piles were executed to assure the new structure to the existing masonry. The contractor advised the client of this improvement to avoid undermines due to potential floods.

\section{Project 3: Masonry extension (Viaduct of Francoli)}

The main structure of AP-7 is an eight hundred metre viaduct which passes over N-2 road and Francolí River. The viaduct is composed of two bridges, which were both widened. New structural elements had to be built and therefore additional piling was required. As noted in Table 2, there were several organizational and project related factors that contributed to rework. From a project perspective the main contributing factors were:

-Client changes or scope extension: Additional works were necessary to the embankments existing structure, which was adjacent to a main highway $(\mathrm{N}-240)$. This highway experiences high levels traffic flow, which were interrupted during the additional works to piling required. In addition, modifications to a load-retaining wall (including drainage) were necessary as a result of the new embankment. A new design was necessary to include these modifications;

- Incomplete contract documentation (omission errors): No specifications about how to join the new framework to the original one, and the unknown technique to adapt the union elements between the new and old structure provoked additional activities; and

- Incomplete analysis of the existing services and soil before the execution: The diversion of some services was not considered in the original design of the project. Thus, additional work which required the localization of services was required (oxygen and nitrogen pipes, oil pipelines and telecommunications).

The main organizational factors were identified as to contributing to the incidence of rework were:

-Organizational re-use: In this instance, the execution or management acquired from previous projects was applied to this project which had negative consequences. For example, pavement joints should have been executed when the tread layer in both sides was being undertaken simultaneously;
- Procedural violations: Tasks of clearing vegetation, illegal waste cleaning after the adjudication and demolition of a concrete pipe that affected the excavation;

- Power struggles between the administration and the management team: Critical decisions were affected by the quest for management control. For example, the client unilaterally chose to pave the driveway instead of repairing the road board first, due to political pressures to ensure the highway could be used by the Easter holidays. This decision was not shared by the client's project management team, although contractor had been instructed by the client directly to commence work without informing the project management team; and

-Lack of resolution solving incidents: The management team was asked to solve many incidences regarding the construction techniques which are normally solved by the contractor without consultations. As a result, the management team was overwhelmed, although it also showed a lack of knowledge in that field, leaving an unreliable image in management.

\section{Project 4: Masonry remodelling}

In this sub-project incomplete contract documentation was again found to be a significant problem. The contract documentation contained numerous design errors which had to be rectified during construction. Normally, to avoid misunderstandings and ensure the project documentation is correct, services position is checked before starting the works. However, due to time constrains, these checks were not carried out. The lack of knowledge about the exact position of electrical and telecommunication services provoked its breakage during the safety fencing works. Other works like the replacement of the pavement in old pillars not included in the project had to be considered while the construction was going on. In addition, activities linked to signalling, marking and site protection also contributed to the cost overrun being experienced.

Lack of inspection and supervision was also pervasive problem within this project. A new management company was chosen to deliver the construction works due to disagreements between client and previous managers. Nevertheless, inexperienced engineers were dealing with the majority of the construction issues. Lack of organisational skills and leadership were latent during this period. Decisions were often taken correctly; however, disconnection existed between management and contractor. Circumstances were complicated when situations such as dealing with traffic operations during the construction process appeared as new issues for the new members of the management team, who did not have experience before on it.

\section{Project 5: Extension of the platform}

From a project perspective the causes of rework in this project were attributable to client changes, incomplete project information and workmanship errors: 
-Clients demands were mainly toll stations, not included in the initial project; complementary works such as car park, or control buildings; cameras movements; collection and replacement of toll traffic lights; collocation of provisional speed radars and emergency stop signals; collection of the signalling of the rest area; safety end user reinforcement during high traffic.

-Other additional activities such exit lanes, signalling road signs, mounting and dismounting of a provisional third lane for weekends, and maintenance tasks during the drainage (cleaning of pipes and wells) were attributed to scope increase.

-Incomplete information within contract documentation such as emergency stop zones; adaptation of the central reservation including passes between 2 and $3 \mathrm{~km}$ to comply the regulation; new signalling board: transportation and collocation of the existing signalling supports to the final position; safety tasks not described in the project; extension of the platform width; new drainage elements such as drainpipes and register wells, adversely influenced the project's critical path especially when requests for information were not forthcoming from the design consultants.

- Incomplete analysis of the existing services and the type of soil before the execution such soil tests to verify its typology was a non-considered cost, but it had an important effect in construction; derivation of existing services which cost money and time dealing with private services companies, and footing changes, it actually make the constructor to bring new machinery. Furthermore, the movement of existing communication pipes and SOS supports were not expected by project managers. Also, the soil tests were not as expected so the inadequate material was replaced with selected material.

- A misunderstood in laws about speed analysis of the end users was a controversial issue. It was not included in the project and this provoked exterior extension (signalling, markers, site protection, etc.) due to visibility problems.

- Unexpected activities such as the demolition of an unexpected flagstone or unexpected lined ditches.

Regarding the organizational factors contributing to rework were:

- The wrong execution or management of previous projects that were latent in the overruns. Some examples are noted: ramps wrongly executed in Project 5 that had to be modified; adaptation of the lines of painting lanes for the high traffic during Eastern (this stretch was supposed to be finished by that time); finishing of the masonry of the previous project; coexistence of different activities from different projects (rigid barriers had to be continuously moved depending on the activities that were carried out); arcades were not executed when planned forced to modify the drainage; reinforcement of the protection of the arcades; reinforcement of the sig- nalling. All these problems came originally from a lack of management, although the new idea of packaging the project and to build it up in separated parts by different contractors caused these subsequent problems.

-Substitution of the management team. Clearly, any change during the construction process impacts in the final result. The substitution of the project management team by another consulting company due to different points of view with the administration was in the most critical moment. The required time for the new management team to adapt to the project provoked the majority of the problems such as not detecting errors and defects until other activities had been started. These problems affected the inspection, supervision and quality control, provoking lack of coordination between the parties.

- Unexpected problems. In this particular project, a great number of unexpected issues appeared: the rain provoked a humidity excess of the central reservation material that had to be reinforced with lime; a ditch construction to address the exceed water to the river; the rain delayed foundation concreting; an accident forced to include stricter safety systems; the high number of heavy traffic that are driving through the old ditch converted into lane during the construction of the new lanes, provoked defects in the pavement and a debilitation of the fibre optic cables; the existing drainage of the central was insufficient and manholes had to be replaced with new drainage; the high quantity of vegetal soil forces to prepare places for the material stocks.

\section{Project 6: Platform extension in stretch 1}

Like Project 5, this project included the major part of the extension of the AP-7 third lane extension. Project 5 and Project 6 belong to the main project, which was divided in two parts, so they come from the same idea in terms of construction, although they are not developed by the same contractor.

The most featured reworks in this project were basically three:

-Client changes or scope extension. Particularly, toll stations were not included in the initial project although the client demanded to cover this overrun as part of the project spending. Shelters and prefabricated elements were not part of the project due to be part of the tolls.

-Incomplete documentation. In prior projects the importance of the uncompleted documentation and design errors on the project was explained. Specifically in this project, the second featured rework was due to the platform extension to improve the visibility while driving.

- Management problems such as wrong execution or management of previous projects as modifications of the lane pavement due to wrong execution work. Moreover, the management problems were similar to Project 5 because it was being constructed when a new management team was announced. However, 
discrepancies between production manager and construction manager existed. Production manager did not solve some incidents during the process, while construction manager could not identify them on time due to the lack of staff. Not enough quality control drove that situation in an endless list of reworks after all.

\section{Project 7: Paving surface and horizontal signalling}

Technical and organisational problems together with other unexpected problems were the major causes of rework.

-Unexpected problems: The high number of heavy traffic that were driving through the old ditch converted into lane during the construction of the new lanes, provoked defects in the pavement and a debilitation of the fibre optic cables and drainage pipes; the use of N-240 as a vehicle access to the site during the execution of the works (more than 5 months) deteriorated the pavement and had to be repaired.

-Scope extension during the execution of the pavement to improve superficial drainage and a correct subterraneous water evacuation.

-Errors in project documentation. The execution procedures of the banking had to be redesigned as the design was impossible to carry out, which would have caused important problems in drainage and stability in cars' driving.

\section{Project 8: Adaptation of the vehicles containment system}

In project 8 , inaccurate project documentation and the lack of knowledge of the management staff were fundamentally the factor contributing to rework. The mana- gement team drew up a new project because the initial one was untreatable. The project modifications provoked no time enough to supervisions and inspections and inappropriate quality control. Other incidences like misunderstandings with the contractor or lack of communication were usual.

Moreover, like in the other sub projects, incomplete project documentation such as extra safety conditions or enlargement of car protections in case of impact provoked rework activities.

Similarly, the incomplete analysis of the existing services and soil before the execution were also a factor contributing to rework. Affected services such as telephony below the containment system in a different position from the project provoked the modification of the collocation of the support of barriers;

\section{Dynamics of rework}

The analysis revealed that no single factor could be used to pinpoint a cause that contributed to rework. As a result, a generic causal model that demonstrates the interdependency exists. Factors are presented and discussed below. Taking into account the factors identified in Table 2, direct observations, interviews with all the parties and documentary sources of the 8 subprojects the influence diagram of rework for each subproject was developed. This information was integrated and implemented in a generic influence diagram of rework and presented in Figure 2. The arrows that link each variable indicate a place where a cause and effect relationship exists, while the plus or minus sign at the head of each arrow indicates the direction of causality between the variables.

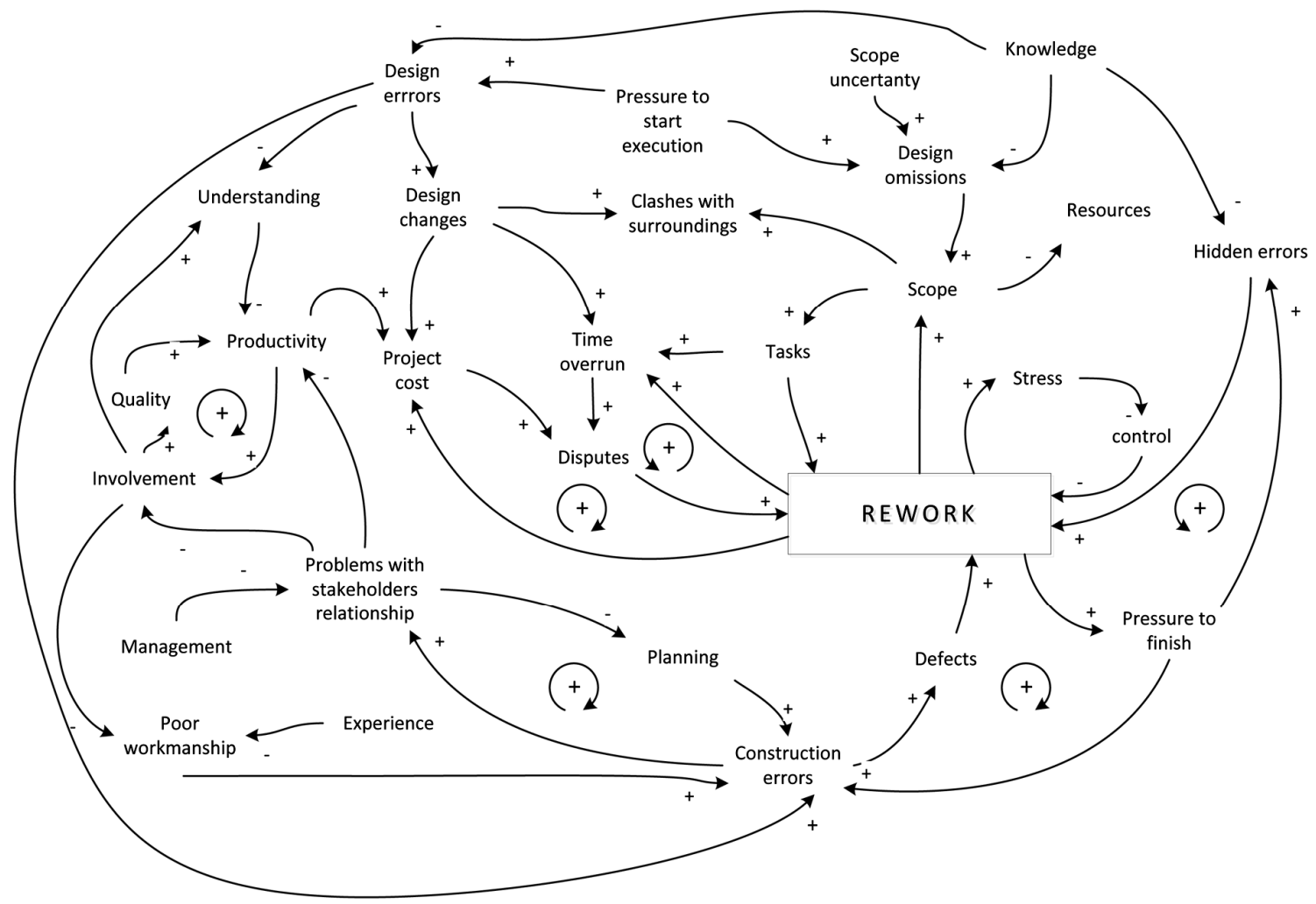

Fig. 2. Generic influence diagram of rework 
Unexpected situations such as inconsistencies between scope, budget and schedule, unanticipated problems or changes often provoke a series of dynamics that can provoke rework and thus create substantial cost and schedule overrun. For example, design changes during construction increased scope and therefore the work to be undertaken. In the case of highway projects rework impact on traffic flow and as a result additional safety are required.

A lack of understanding and knowledge of client requirements hindered scope development, increased workload which subsequently subjected consultants to schedule pressure. As a result, design errors and omissions arose in the contract documentation. This was mainly because design audits, reviews and verifications where not adequately undertaken (Love et al. 2010a). Such errors and omissions were not identified until construction was being undertaken. The time to rectify the error can affect the progress of the work or even require a design change and thus lead to cost increase and time overruns. The later design errors are identified in the project cycle the more costly they are likely to rectify, especially once construction has commenced.

Scope uncertainty is an innate feature in highway construction. In the case study presented, it arose primarily due to client inexperience dealing in multiple simultaneous contracts. Highway projects in Spain have tended to be procured using the traditional lump sum method. The requirement of contractor involvement during the design process can improve constructability and reduce the probability of design changes. When there is scope uncertainty and no contractor involvement during design then the likelihood of design changes increases, which may increase project costs and time and lead to claims and disputes (Love et al. 2012b).

Similarly, productivity is affected by work quality, availability of prerequisites, out-of-sequence work, schedule pressure, morale, skill and experience, organizational size changes and overtime (Lyneis, Cooper 2001). In the same way, stakeholders' relationship and differences between design team and contractors can make planning difficult, as they may have differing goals and objectives. In this case study the consultants had not worked with the contractor before and there was a great deal of tension and reluctance for parties to work together. The contractor perceived that the lack of knowledge and poor contract documentation produced by the designers inhibited the development of teamwork and joint problem solving. As the project progressed and design errors became increasingly prevalent, the more time the contractor spent trying to solve the problems that arose on site.

\section{Discussion}

Although little systematic knowledge is available on the dynamics of rework in construction projects, generic systemic models of rework have been developed for residential apartments (Love, Mandal 1999; Love et al. 2008) and for complex hydrocarbon (oil and gas) projects (Love et al. 2011).
Both studies related to building construction projects (Love, Mandal 1999; Love et al. 2008) revealed that most of the rework experienced was generated from the conception and design stages of the projects. Mainly poor quality of the documentation and design errors provoked changes to be implemented during construction.

Although no generic systemic model of rework has been developed for civil infrastructures, the analysis of 115 civil infrastructure projects revealed that the ineffective use of IT by design team members was the primary factor contributing to rework in this kind of projects (Love et al. 2010b). This finding is in line with those obtained in construction engineering projects and also with the results of this study and means that the design stage is the most important one to reduce rework.

In the case study presented, akin to Love and Mandal (1999) it was found that poor skill levels of the management team provoked a lack of resolution solving problems. In the same way, the lack of attention to coordinating and integrating the existing services with the drawings was found to contribute to rework. Design reviews and verifications and selection of appropriate firms on the actual skill level and experience of those staff that are actually going to manage the project's design process are some suggestions to minimize errors and thus rework.

Akin to building construction projects and the results of this study, the factors of poorly defined scope, unrealistic schedules, design changes, and coordination problems were identified as contributors to rework in complex hydrocarbon (oil and gas) projects (Love et al. 2011). However, in complex hydrocarbon projects rework was expected and considered a norm. The issue at hand therefore related to 'when and where' rework would materialize, because it was considered that the implementation of front end loading, audits, and reviews would capture any design flaws that may have materialized. The potential revenue that could be generated from earlier extraction and production of oil and gas outweighed any rework costs that were likely to be incurred (Love et al. 2011). This is not the case of public infrastructures such as highways.

The major difference regarding rework between highway infrastructures and other civil engineering works identified in this case study was the need to deal with surrounding aspects such as traffic operations during the construction process providing provisional lanes for the traffic or dealing with accidents when they occurred.

On the other hand, the particularity that each subproject was competitively awarded under a separate works contract provoked misunderstandings between the parties involved and therefore the majority of the organisational problems.

Finally, the degree of uncertainty that prevails within transportation infrastructure projects was also a particularity of highway infrastructures together with ambiguous and poor project documentation and changes made at the request of the client where also found to be determinants to contribute to rework. 


\section{Conclusions}

In Spain there is limited systematic knowledge available about the dynamics of rework in highway projects, despite the fact that they frequently exceed budget and schedule by more than $10 \%$. A major factor contributing to cost and schedule overruns is rework. In this paper, the factors contributing to rework on a major highway project were identified and used to produce a generic systemic model that illustrates the relationships between variables.

Through observation and subsequent analyse of interviews and documentation a high degree of interdependency existed between perceived causes. This resulted in the nomenclature of Project, Organization and People to be adopted and used to develop the rework generic systemic model.

The research findings are akin to so similar studies and therefore confirm the reality of the rework phenomena in projects. Notably the risk of scope changes, high complexity, poor skill levels and unexpected underground services were systematically underestimated during the design and planning process to produce and therefore an unrealistic forecast of project costs and schedule was made.

Understanding how variables interact with one another and the variables that contribute to rework provides a new view to be acquired that can lead to behaviour adjustment. This may be achieved by formally recognizing rework as a key performance indicator within public infrastructure contracts and linking it to a risk/reward model of compensation. It is suggested that this would stimulate learning and process improvements for future highway projects.

Project managers are often confronted with having to make decisions based on an imperfect and incomplete knowledge of future events. This is particularly the case contract documentation is incomplete and contains errors. One approach to improving managerial decision-making is to quantify uncertainties using probability.

Future research should focus on developing probabilities and impacts of risk that arise from the contract documentation process of a project, particularly the interaction between risks. The use of probabilistic network models, such Bayesian networks are a suitable tool for measuring and managing rework in projects due to their ability to take into causal relations.

\section{References}

Alessandri, T.; Ford, D.; Lander, D.; Leggio, K.; Taylor, M. 2004. Managing risk and uncertainty in complex capital projects, The Quarterly review of economics and finance 44(5): 751-767. http://dx.doi.org/10.1016/j.qref.2004.05.010

Barber, P.; Sheath, D.; Tomkins, C.; Graves, A. 2000. The cost of quality failures in major civil engineering projects, International Journal of Quality and Reliability Management 17(4/5): 479-492. http://dx.doi.org/10.1108/02656710010298544

Burati, J. L.; Farrington, J. J.; Ledbetter, W. B. 1992. Causes of quality deviations in design and construction, Journal of Construction Engineering and Management 118(1): 3449. http://dx.doi.org/10.1061/(ASCE)07339364(1992)118:1(34)
Cooper, K. G. 1980. Naval shipyard production: a claim settled and a framework built, Interfaces 10(6): 30-36. http://dx.doi.org/10.1287/inte.10.6.20

Cooper, K. G. 1993. The rework cycle: benchmarking for the project manager, Project Management Journal 24(1): 17-22.

Dissanayake, G. M.; Fayek, A. R.; Campero, O.; Wolf, H. 2003. Measuring and classifying construction field rework: a pilot study, in Proceedings CSCE Annual Conference, 5th Construction Specialty Conference, 4-7 June, 2003, Moncton, Canada, 1-7.

Fayek, A. R. 2004. Developing a standard methodology for measuring and classifying construction field rework, $\mathrm{Ca}$ nadian Journal of Civil Engineering 31(6): 1077-1089. http://dx.doi.org/10.1139/104-068

Flyvbjerg, B. 2006. Five misunderstandings about case-study research, Qualitative Inquiry 12(2): 219-245. http://dx.doi.org/10.1177/1077800405284363

Hwang, B.; Thomas, S. R.; Haas, C. T.; Caldas, C. H. 2009. Measuring the impact of rework on construction cost performance, Journal of Construction Engineering and Management 135(3): 187-198. http://dx.doi.org/10.1061/(ASCE)07339364(2009)135:3(187)

Jefatura de Estado 2007. Ley 30/2007 de Contratos del Sector Público, Madrid. 101 p.

Kvale, S. 1996. Interviews: an introduction to qualitative research interviewing. Thousand Oaks: Sage. 326 p.

Love, P. E. D.; Mandal, H. L. 1999. Determining the causal structure of rework influences in construction, Construction Management and Economics 17(4): 505-517. http://dx.doi.org/10.1080/014461999371420

Love, P. E. D. 2002. Influence of project type and procurement method on rework costs in building construction projects, Journal of Construction Engineering and Management 128(1): 18-29. http://dx.doi.org/10.1061/(ASCE)07339364(2002)128:1(18)

Love, P. E. D.; Edwards, D. J. 2004. Forensic project management: the underlying causes of rework in construction projects, Civil Engineering and Environmental Systems 21(3): 207-228.

http://dx.doi.org/10.1080/10286600412331295955

Love, P. E. D.; Edwards, D. J.; Irani, Z. 2008. Forensic project management: an exploratory examination of the causal behavior of design-induced error, IEEE Transactions in Engineering Management 55(2): 234-248. http://dx.doi.org/10.1109/TEM.2008.919677

Love, P. E. D.; Davis, P. R.; Ellis, J. M.; Cheung, S. O. $2010 \mathrm{a}$. A systemic view of dispute causation, International Journal of Managing Projects in Business 3(4): 661-680. http://dx.doi.org/10.1108/17538371011076109

Love, P. E. D.; Edwards, D.; Watson, H.; Davis, P. 2010 b. Rework in civil infrastructure projects: determination of cost predictors, Journal of Construction Engineering and Management 136(3): 275-282.

http://dx.doi.org/10.1061/(ASCE)CO.1943-7862.0000136

Love, P. E. D.; Davis, P. R.; Cheung, S. O.; Irani, Z. 2011. Causal discovery and inference of project disputes, IEEE Transactions on Engineering Management 58(3): 400411. http://dx.doi.org/10.1109/TEM.2010.2048907

Love, P. E. D.; Edwards, D. J.; Irani, Z.; Goh, Y. M. 2011. Dynamics of rework in complex offshore hydrocarbon projects, Journal of Construction Engineering and Management 137(12): 1060-1070.

http://dx.doi.org/10.1061/(ASCE)CO.1943-7862.0000377 
Love, P. E. D.; Edwards, D. J.; Irani, Z. 2012a. Moving beyond optimism bias and strategic misrepresentation: an explanation for social infrastructure project cost overruns, IEEE Transactions on Engineering Management 59(3): 560571. http://dx.doi.org/10.1109/TEM.2011.2163628

Love, P. E. D.; Wang, X.; Sing, C-P.; Tiong, R. 2012b. Probability of project cost overruns in Australian construction and engineering projects, Journal of Construction Engineering and Management (in Press).

Lyneis, J. M.; Cooper, K. G.; Els, S. 2001. Strategic management of complex projects: a case study using system dynamics, System Dynamics Review 17(3): 237-260. http://dx.doi.org/10.1002/sdr.213

Montes, G. M. 2007. Work risk-prevention procedures in highway management and maintenance contracts, Human Factors and Ergonomics in Manufacturing \& Service Industries 17(3): 229-244. http://dx.doi.org/10.1002/hfm.20061

Morse, J.; Richards, L. 2002. Readme first for a user's guide to qualitative methods. London: Sage Publications. 262 p.

Ministerio de Fomento. 2011. Anuario Estadístico. Madrid: Dirección General de Carreteras del Ministerio de Fomento. $472 \mathrm{p}$.

Palaneeswaran, E.; Love, P. E. D.; Kumaraswamy, M. M.; $\mathrm{Ng}, \mathrm{T}$. S. T. 2008. Mapping rework causes and effects using artificial neural networks, Building Research and Information 36(5): 450-465. http://dx.doi.org/10.1080/09613210802128269

Ragin, C. C. 1994. Constructing social research: the unity and diversity of method. Thousand Oaks, Calif: Pine Forge Press. 194 p.
Rodrigues, A.; Bowers, J. 1996. The role of system dynamics in project management, International Journal of Project Management 14(4): 213-220.

http://dx.doi.org/10.1016/0263-7863(95)00075-5

Rogge, D. F.; Cogliser, C.; Alaman, H.; McCormack, S. 2001. An investigation of field rework in industrial construction. Construction Industry Institute, University of Texas at Austin, Austin, Texas.

Silverman, D. 2001. Interpreting qualitative data. London: Sage. 325 p.

Williams, T.; Eden, C.; Ackermann, F.; Tait, A. 1995. Vicious circles of parallelism, International Journal of Project Management 13(3): 151-155. http://dx.doi.org/10.1016/0263-7863(95)00034-N

Williamson, O. 1979. Transaction cost economics: the governance of contractual relations, The Journal of Law and Economics 22(2): 233-261. http://dx.doi.org/10.1086/466942

Wolstenholme, E. 1990. System enquiry: a system dynamics approach. New York: John Wiley \& Sons, Inc. 238 p.

Yin, R. K. 1984. Case study research: design and methods. Newbury Park: Sage Publications. 160 p.

Zhang, D.; Haas, C.; Goodrum, P.; Caldas, C.; Granger, R. 2012. Construction small-projects rework reduction for capital facilities, Journal of Construction Engineering and Management 138(12): 1377-1385. http://dx.doi.org/10.1061/(ASCE)CO.1943-7862.0000552

Znaniecki, F. 1934. The method of sociology. New York: Farrar and Rinehart. 338 p.

Nuria FORCADA is a Lecturer in the Department of Construction Engineering at Universitat Politecnica de Catalunya (UPC). She is a member of the Group of Construction Research and Innovation (GRIC) that conducts interdisciplinary research to improve the productive processes of the construction sector companies. She received her PhD from the UPC. Her research interests include quality and defect management, collaborative working environment, knowledge management, decision making systems and e-learning.

Gerard RUSIÑOL is a Civil Engineer graduated from Civil Engineering School of Barcelona (ETSECCPB) at Universitat Politècnica de Catalunya (UPC) with 3-year work experience in roads and structures, driving project and management duties. He also holds a Master's Degree in Civil Engineering, majoring in Structures and Construction, and minoring in Water Engineering, Hydrology and Hidrodynamics. He worked in the Department of Construction Engineering at UPC determining the causal structure of rework in highway projects as a result of his Master's Final Thesis.

Marcel MACARULLA is a researcher and Assistant Lecturer in the Department of Construction Engineering at Universitat Politecnica de Catalunya (UPC). His research interests include construction productivity improvements, predicting methods and environmental impacts of rework and new technologies.

Peter E. D. LOVE is a John Curtin Distinguished Professor and holds an Endowed Chair in Building Information Modelling at Curtin University. He is a Fellow of the Royal Institute of Chartered Surveyors (FRICS) and recipient of 2010 Scopus Young Australian Researcher of the Year Award (Humanities and Social Science) and a member of the Australian Research Council's Engineering and Environmental Science Panel for the 2010/11 Excellence in Australian Research Exercise. Professor Love has co-authored/edited six books and has authored/co-authored over 500 internationally refereed research papers, which have appeared in leading international journals such as Accident Analysis and Prevention, Journal of Management Studies, Journal of the Operational Research Society, European Journal of Operations Research, European Journal of Information Systems, IEEE Transaction on Engineering Management, and International Journal of Production Economics. 